\title{
Interview with Martin Enderle on "Possibilities and Limitations of Virtualization in Online Markets"
}

Chief Executive Officer (CEO) Dr. Martin Enderle is responsible for strategic advancement, organization, and integration of the Scout24-Group as well as of all participating markets. $\mathrm{He}$ is spokesman of the group and also CEO of the Immobilien Scout GmbH. Dr. Martin Enderle was born in 1965. He studied mathematics at the University of Karlsruhe and at King's College London and later received his doctorate at the University of Hanover. From 1995 until 1999 he worked for McKinsey \& Company in Hamburg focusing on automobile and telecommunication industry. In 1999 he moved to Munich and built up the German branch of the venture capital enterprise Speed Ventures. In the following two years Speed Ventures founded and financed about 30 Internet and technology enterprises. In 2001, Dr. Enderle started working for T-Online where he initially managed international business and participations. He was successful in restructuring these in many European countries and leading them to profitability. As person in charge for M\&A at T-Online Dr. Enderle was responsible for the acquisition of Scout24 in 2004 and later gained a position in the advisory board of Scout24. In June 2005 he took over the management of the Scout24 Holding GmbH and has additionally been working as CEO of the Immobilien Scout GmbH in Berlin since April 2008.

DOI 10.1007/s12599-008-0003-6

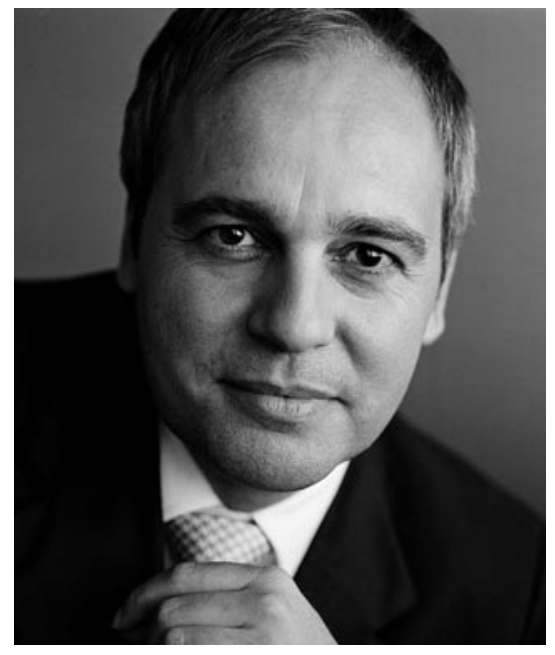

Dr. Martin Enderle CEO Scout24 Holding GmbH Rosenheimer Str. $143 \mathrm{~b}$ 81671 Munich, Germany martin.enderle@scout24.com

\section{Interview by}

Prof. Dr. Hans Ulrich Buhl Maximilian Röglinger University of Augsburg Department of Information Systems Engineering \& Financial Management Universitätsstraße 16

86135 Augsburg

Germany

\{hans-ulrich.buhl | maximilian. roeglinger\}@wiwi.uni-augsburg.de

This article is also available in German in print and via http://www.wirtschafts informatik.de: Interview mit Martin Enderle zum Thema „Möglichkeiten und Grenzen der Virtualisierung in Online-Marktplätzen“. WIRTSCHAFTSINFORMATIK. doi: 10.1007/11576-0080107-0.
BISE: Virtualization aims among other things at mapping real-world structures and processes to information and communication systems. Especially end-users and individuals profit from an information offer enhanced by virtualization when doing online research. Regarding this issue, what kind of possibilities do online markets already offer today?

Enderle: At our Scout 24 markets there are various approaches which have one thing in common: They are successful in making product experience much more concrete and emotional. By means of videos, animations, and likewise, user involvement in the digital information process is increased considerably. Objects and services become perceptible and thus are easier to imagine than by means of static result lists. User behavior within online research as well as their requirements as regards quality and treatment of information has changed in recent years. Customers are more demanding but have 
increasingly less time. They are not willing to spend this scarce resource on a laborious and time-consuming information process. Therefore, they expect personalized solutions for all relevant areas of life which ease decision making. This also includes virtualized offers that may be accessed digitally, and thus quickly, easily, and at any time.

We have extensively thought about what kind of opportunities exist for Scout 24 as regards this issue. One part of our vision has already been realized at our market places, e.g. the virtual apartment and house inspection at ImmobilienScout 24 . Photos of individual objects have been a usual standard within this market for a long time. However, significant added value for the users can be generated by videos which enable them to go on a virtual tour through selected properties. Similar to an inspection at the location itself, the customer moves through the rooms and receives a three-dimensional impression of his potential domicile. In the same way it is possible to explore the environment or the entire city of the respective object. Is it an apartment in the country or is there a highly frequented road nearby? For families with children for instance it might be decisive which child care facilities or shops for everyday needs are close. At ImmobilienScout24 therefore we provide our users with virtual maps in cooperation with Microsoft that have been enriched with the mentioned and further useful information. Such impressions and additional information edited with multimedia support extend the decision space considerably - a simple textual description cannot keep up with these. However, an actual inspection, which additionally offers sensory experience beyond a merely visual one, cannot be replaced.

BISE: Now you are moving on to a supposed limitation of virtualization. Where do you see these limits?

Enderle: Limitations of virtualization can primarily be found in those cases where it finally is a matter of real, material objects. There the user wishes to experience and touch products before making a purchase decision. This experience can theoretically be implemented virtually if the user enters a virtual world with haptic and olfactory impressions wearing a cyber-dress. But for the mass market these are future visions. So far, the virtual inspection of properties does not replace the final visit of the location. The selec- tion process can be digitalized more and more, but not the products themselves. An apartment can only be virtualized to a certain degree - in the end it stays a real object.

The same holds in our case e.g. for searching a vehicle. Currently, concepts for virtual test drives are in development. There the user is enabled to not only look at the car statically by means of photos but to experience it by means of a 3D test drive. This makes the personal impression even more detailed, though the required haptic dimension is not realized in this case either. How do the seats or individual materials of the interior feel? Does the car paint look that bright in reality as well? Today these questions can only be answered by visiting the car dealer. This again results from the fact that the product is a real one that only has been "imported" to a virtual world.

We are able to inform our customers with respect to their specific requirements in a detailed way and thus provide all of the necessary information they need for decision making. However, in my opinion, we so far cannot entirely compensate for the wish for a realistic experience in the case of these products. Another limitation, resulting from a technology-oriented perspective this time, is the presentation quality. For the time being this still is a limitation in the course of a more stringent realization of virtual concepts. Here future will show what kind of improvements are to be found.

BISE: You have already depicted an example for virtual offers provided by the Scout24-group by mentioning virtually accessible apartments. What other examples for virtualization does your enterprise provide?

Enderle: We have already opened one door towards virtual worlds. In this case our users cannot only exchange experiences and products but also meet virtually. Especially with FriendScout 24 the representation of our users as digital profiles is a growing world. They can meet in groups in virtual worlds depending on their interests. In the course of these virtual dates they can overcome barriers of establishing contacts more easily. People do not just encounter in the meatspace but profiles interact in a virtual way and try to find out similarities. Another example for virtual offers in our group is "my finance folder" at FinanceScout24. Here you are not only able to buy financial or insur- ance products but also to keep all documents such as contracts, invoices, or policies. Besides time you can also save physical space and material resources.

Moreover, our online travelling market place TravelScout 24 shows that counseling interviews about products need not necessarily take place in reality but can be performed by means of chats. Service center employees respond to the individual needs of the customers. In analogy to speaking with the customer in the travel agency, holidays can be booked immediately or later. Due to this possibility the personal contact to the travel agency becomes obsolete because the chat counseling is available late in the night or at weekends as well. This saves an enormous amount of time and means additional comfort for our users.

BISE: Objects as well as services do exist in the real world and are "imported" to the virtual world. What kind of merely digital or virtual objects can you imagine?

Enderle: Everything that can only be consumed or perceived in the online world is a virtual object. We make use of those possibilities of virtualization as far as we can and consider them to be useful. Of course more and more virtual products will be developed and be traded online together with imported objects. I can imagine for instance that time as a scarce resource might also virtually become a marketable good by offering and also performing it as a service in the virtual space. This may sound abstract. However, in a society of services where the resource time becomes scarce we must increasingly also expect concepts and business models that encounter this shortage with respective offers. Another possibility might be trading with reputations. This includes mutual evaluation of profiles, mutual higher ranking to win the favor of the target group. Of course these are mere thoughts - if and how such products might be developed remains to be seen.

BISE: Your examples give an insight into the different possibilities that provide users with a concrete and emotional product experience. How do the users themselves accept these possibilities?

Enderle: User acceptance goes along with an increasingly active search in the Internet and the need for overall information before decision making. It has to be kept in mind that technological developments and the increasing diffusion of the Internet offer the possibility to pro- 
vide more and more information. According to the $2008 \mathrm{ARD} / \mathrm{ZDF}$ online study already $65.8 \%$ of all Germans have access to the Internet, $70 \%$ of these use broadband Internet access. The diffusion of this high-performance access will even grow further and thus also bandwidth itself will increase. Our monitoring as regards acceptance of virtual offers came to the result that our users demand and use moving images and 3D-presentations of products.

Known and learned things are a pasttime issue. Today, testing, experimenting, and "multiplying" possibilities is important. It can be imagined that the user enters a virtual car dealer while looking for a new car. There he can choose between different models which, in contrast to real life, are already filtered according to his previously filled individual profile of needs and desires. He can walk from car to car, have a look at the specific interior equipment, and leave for a virtual test drive. Considering the increasing bandwidth we can imagine - at least theoretically - that these dreams of the future become true. This is similar to looking for properties. Our users already thankfully accept the virtual tour through apartments and houses. The next step to ease decision making is the three-dimensional mapping of ground plans which enables furnishing the apartment in advance.

BISE: What kind of concrete added value do users receive by virtualized offers, especially in contrast to "conventional" offers?

Enderle: The Scout24-Group is one of the leading groups of online market places in Germany and Europe. We provide users with a simple way of finding products, services, or objects easily and efficiently. It will not easily be possible to virtualize cars, apartments, or holidays in future either. But we have added diverse virtual offers to our markets which improve the users' experience and thus generate added value. By means of the already mentioned "Added Services", such as virtual car dealers or $3 \mathrm{D}$ ground plans of properties for instance, the preselection process is improved significantly. Users receive broader information on the chosen object than in mere text advertisements. Such services are fun and satisfy the customers' need of not only looking at things two-dimensionally but also experiencing them three-dimensionally. They provide users with the necessary inspira- tion to make the best decision from their personal point of view. Thus, virtual offers also ease the selection process and make it easy to experience, concrete, and also omnipresent by means of mobile devices. If the lifestyle of modern consumers combines flexibility and mobility and is dominated by self-realization, also the living space has to be adapted.

BISE: So much for the existing or planned virtual offers. In which direction will the market develop in the following years according to your opinion?

Enderle: Social development and acceptance of innovations are progress drivers towards a possible full virtualization. In the end questions on efficiency arise over and over again. Let us for instance imagine the cyber world I suggested before into which the user can dive completely and make all sensory experiences as in the real world. Offering and using these worlds would require enormous computing capacities and exhaust the bandwidth of the Internet. Thus, business activities border on a social or rather ecological responsibility. In our enterprise the user constitutes the center of all activities but, if in the end economic activities do not add up to sustainable activities, no one will benefit. Therefore we currently consider scenarios and ask ourselves what kind of support our consumers need in which situations of their lives in order to make an important decision within our offers. At the moment, data volumes are located at an acceptable level; however, informationbased added value and saved resources such as time and space have grown exponentially due to the described features.

BISE: Dear Mr. Enderle, thank you very much for this interview. 